\title{
Physician-to-patient Direct Primary Care: Entrepreneurial Country Doctors Offer a NewMedical Business Model ${ }^{\mathrm{i}}$
}

\author{
Robin S. McCutcheon ${ }^{1, *}$, Lori, McCoy, D.O. ${ }^{2}$ \\ ${ }^{1}$ Lewis College of Business, Marshall University, United States \\ ${ }^{2}$ Advanced Primary Care, United States
}

Copyright $\odot 2019$ by authors, all rights reserved. Authors agree that this article remains permanently open access under the terms of the Creative Commons Attribution License 4.0 International License

\begin{abstract}
Starting in 1942, the United States federal government introduced five major healthcare policies with the intention of reducing the cost of healthcare while insuring millions of people without health insurance. These actions have steered the country towards a monopolistically competitive posture in the medical industry, and compelled consumers to purchase services from few companies at progressively higher prices. The laws of supply and demand cannot be changed, altered, or forced into contortions outside of their nature. Rather than work against market forces, the answer to monopolistic competition is to decentralize the market. Increasing competition for the consumer-patient using common sense, transparent pricing and visible menu lists in physicians' offices will lead to lower market prices for goods and services.
\end{abstract}

Keywords Healthcare, Low-cost Healthcare, Entrepreneurial Micro-practice, Business Medicine

\section{Introduction}

Since 1942, United States federal government policy and regulatory overreach into the medical industry has led to a higher concentration of medical insurance companies in that industry. Five major injections of federal government policy, at the behest of the American Medical Association lobbyists and medical insurance companies, have resulted in a medical insurance industry that is closer to a single payer system, than a decentralized industry in which physicians practice medicine as small business entrepreneurs. Economists know that highly concentrated industries increase market prices due to lack of competition among businesses. Consumers have no recourse in selecting substitute goods or services in highly concentrated industries -as there are no substitutes. The few businesses occupying a highly concentrated industry are free to keep market prices higher than in a competitive market.

In the market for medical insurance, third party payers obscure the market price from consumers wishing to purchase healthcare from their physicians. With no guiding market mechanism to inform the consumer which service will suit their pocket book best, consumers have little interest in being prudent with the money they spend -because the money they are spending isn't theirs -it's the insurance company's money. This market fails for two reasons: there is no market mechanism to inform consumers' budgeting choices, and the consumer feels free to spend money that doesn't originate from their own wallet. Thus, in an economic environment in which consumers may demand as much healthcare as they wish, without serious penalty to their own pocketbook, the demand for healthcare increases without bound resulting in ever-rising prices.

The only way to hold down prices for medical services in a single-payer system is to keep consumers from using it (which economists call rationing). In a decentralized economy, consumers themselves choose to ration their own purchase of medical care according to how dear the service will be to their budget. The difference between the rationing choices comes down to the person making the decision to ration the service: some nameless faceless bureaucrat, or the patient. The nameless faceless bureaucrat will not have the patient's best interest at heart; rational self-interest demands we allow the patient to use his own self-interest to make his own decisions.

The next four sections contain a brief history of healthcare policies to sketch the picture of our current predicament in the healthcare controversy, followed by a common sense solution to affordable healthcare with a brief example of how well the solution works for 
low-income individuals, and a discussion of the success of this new business model. We conclude with the notation that further research involving case studies at local, state, and national levels is desperately needed to evaluate the efficacy of this distribution of healthcare.

\section{A Brief History of Healthcare Policies in the United States}

The earliest known healthcare coverage in the United States started in 1798, when Congress established the U.S. Marine Hospitals. (Scofea, 1994) The earliest insurance benefits covered lost wages (due to accidents or illness) rather than health care services. (Scofea, 1994) The first accident policy recorded was underwritten by Franklin Health Assurance Company of Massachusetts in 1850, and was followed by Travelers Insurance Company in 1863. Mining, lumber, and railroad companies developed employee medical plans in the several decades following 1870s. The first known plan was developed by Western Clinic in Tacoma, Washington and was quickly followed by another two-dozen group clinics. By the end of the nineteenth century, nearly 50 insurers covered almost half a million policies. (Scofea, 1994)

At the turn of the twentieth century Aetna Life Insurance Company joined with Travelers Insurance to underwrite insurance against "loss due to temporary total disability occasioned by all diseases except tuberculosis, venereal disease, insanity, or disabilities due to alcohol or narcotics," and promoted it in cities with populations in excess of 5,000. (Scofea, 1994) In 1910, Montgomery Ward and Company joined the fray offering its employees insurance to protect them against loss of income due to illness or injury. This is commonly regarded as the first true group health insurance policy. (Scofea, 1994) These were only a few companies of many that offered health insurance prior to World War II (WWII), and basic health care decisions made by regular citizens were made in the atmosphere of competitive markets.

Prior to World War I (WWI) growing support for compulsory health insurance coverage was led by the progressive movement from Europe, and established in the United States by I.M. Rubinow, the founder of the American Association for Labor Legislation. The stated intention was to relieve poverty caused by sickness by redistributing individual wage losses and medical costs through insurance and reduce the social costs of illness by providing effective medical care while creating monetary incentives for disease prevention. (Scofea, 1994) But Rubinow knew that by redistributing money through a variety of smoke and mirrors moves, whoever controlled the purse strings, would control people's health care decisions. The original opponent to this movement was, remarkably, the president of the American Federation of Labor (AFL), Samuel Gompers, as well as physicians and insurance companies. (Scofea, 1994) Gompers didn't want a government insurance system because he thought it would weaken the unions. Independent physicians didn't want government insurance because they objected to government control of their practices and fee structures. WWI ended without the compulsory health insurance legislation. With the election of Franklin D. Roosevelt in 1932, the New Deal legislation implemented by congress during the late 1930s and WWII, the stage was set for the renewal of the notion of government-sponsored health insurance. Slowly, nationalized healthcare began to gain ground with politicians and the general public. (Scofea, 1994)

The 1942 Stabilization Act imposed wage and price controls on U.S. businesses ostensibly limiting the ability to pay higher wages to attract workers in the scarce labor market during WWII. The act allowed workers to avoid tax penalties on non-income wages, like health care insurance and benefits. This favorable tax treatment led to explosive growth in commercial health insurance. Prior to 1939 approximately $10 \%$ of civilian workers had health care coverage, but by 1955 , employers covered nearly $70 \%$ of the labor force. (Kongstvedt, 2016) The healthcare insurance market was competitive and consumers paid relatively low prices for catastrophic health insurance.

At this particular time, basic healthcare as administered by general or family practice physicians was fee-for-service and out-of-pocket for consumers on a sliding scale based on the consumer's ability to pay. (Hall \& Schneider, 2008) Hall and Schneider state, "Sliding scales flourished not because of ethical edicts but because they were an economic advantage or even necessity. When the cross-subsidies of insurance premiums replaced the cross-subsidies of the sliding fee scale, the tentative professional ethic of that scale yielded to the market ethic of standard fees. Insurance drove a standardization of fees, which prevented not only surcharges, but also some discounts. For instance, the federal government prohibited physicians from waiving the portion of their fees payable by Medicare patients (lest patients be encouraged to overuse Medicare)." (2008) The sliding scale method of determining the price of an office visit to the family physician did not survive the 1965 Medicare \& Medicaid legislation. (Hall \& Schneider, 2008)

In 1965, congress took the second major step towards single-payer medical insurance system with the passage of two landmark entitlement programs: Medicare for the elderly, and Medicaid for the indigent and their dependents. This combination of Medicare, Medicaid, private insurance, and other minor federal programs, resulted in a third-party payment system in which the price of health care was obscured from patients because someone else was paying their medical bills. (Kongstvedt, 2016) Because the third-party payment system disconnects the patient from the price he pays for medical care the patient thinks the medical visit is "free", and following the economic Law of 
Demand, anything "free" will be demanded without bounds. Thus, the demand for health care skyrocketed, pushing up prices and increasing utilization. Hall and Schneider state, "Insurers negotiate with doctors and hospitals for low rates for covered patients, and doctors and (especially) hospitals try to recoup what they cede in this bargaining by charging uninsured patients more." (2008) We can see that upward pressure on the demand for healthcare by the insured patient increases prices for the uninsured patient, who is paying for the medical visit out-of-pocket.

The third step towards single-payer medical insurance system was accomplished in 1973, when congress passed the Health Maintenance Organization Act (HMO). (Kongstvedt, 2016) The intention of this act was to allow Medicare beneficiaries to enroll in HMOs so that the pre-paid group practice interaction between private insurance and fee-for-service providers would be an incentive to control the rising costs of healthcare. Once again, the consumer-patient was disconnected from seeing the true market price of the medical visit/care, and by paying a low office visit fee gave the illusion that medicine was cheap. The Law of Demand in economics states that when the price decreases the quantity demanded increases, so utilization of medical care/visits increased, pushing up prices, again. To curtail (ration) the upward pressure on the demand for medical services, HMO-type plans restricted consumer-patient access to 'within network' physicians.

For the duration of the 1980s, the introduction of the prospective payment system ${ }^{1}$ resulted in an increase in the number of patients staying overnight in hospitals for treatment, and decreasing the length of hospital stay treatment periods. For the resident physician it meant busier days and nights, greater stress and fatigue, and a movement from general practice to specialty care. (Ludmerer \& Johns, 2005; McCutcheon, 2009) Total physician supply was projected to increase rapidly relative to the population for the next 30 years. (McCutcheon, 2009)

By the end of the 1980s, the growing concern of many was that too many resident physicians were choosing a variety of specialties in medicine rather than the primary care specialty. (McCutcheon, 2009) The College on Graduate Medical Education (COGME) recommended the total number of first-year residency positions be constrained to $110 \%$ of the number of US medical graduates while increasing by $50 \%$ the number of residents entering primary care disciplines. The hope was that with good incentives, new residents would choose primary care

\footnotetext{
1 The Medicare Prospective Payment System (PPS) was introduced by the federal government in October, 1983, as a way to change hospital behavior through financial incentives that encourage more cost-efficien management of medical care. Under PPS, hospitals are paid a pre-determined rate for each Medicare admission. Each patient is classified into a Diagnosis Related Group (DRG) on the basis of clinical information. Except for certain patients with exceptionally high costs (called outliers), the hospital is paid a flat rate for the DRG, regardless of the actual services provided. 4/13/2009: http://www.ahd.com/pps.html
}

as their specialty without leaving the AMA in the unfortunate position of having too many general practitioners and not enough specialists. (Cooper, 1994; McCutcheon, 2009)

At this time, resident doctors were not counted in the overall physician workforce effort because they spent more time in specialty training than in primary care areas. (Cooper, 1994, Rivo, et al., 1995; McCutcheon, 2009) Finally, it was believed, the managed care sector had created the largest demand for primary care physicians ever, and while recruitment was in full swing for non-physician providers (NNPs) ${ }^{2}$ the data suggested that the current fee-for-service number of primary care givers were sufficient. (Cooper, 1994; McCutcheon, 2009) ${ }^{3}$

In 1998, the AMA concluded that the number of residents in training was well beyond the number necessary for the national physician workforce, and that since Medicare funding would be reduced because of the 1997 Balanced Budget Act, so too should the number of GMEs (residency training positions). (Dunn, et al., 1998; McCutcheon, 2009) But, by the next year, 1999, the AMA stated that there was 'no systematic planning to ensure that the appropriate number, distribution, and balance of specialties are represented in the health care system for the ensuing decades.' (Miller, et al., 1999; McCutcheon, 2009) In addition, the AMA stated that there was 'no systematic planning mechanism to determine the total number of practicing physicians, and therefore, the total number of GME trainees required for the US health care system' was in existence either. (Miller, et al., 1999; McCutcheon, 2009) In other words, the AMA did not know how to determine the correct number of family/general practice physicians the market would bear, nor did they know how to coerce resident physicians (GMEs) to elect to be family/general practice physicians rather than any other specialty. Simply put, the AMA could not force the market for physicians into a contortion that decentralized markets would support. ${ }^{4}$

In 2003, the fourth step towards single-payer medical insurance system was initiated by the passage of the Medicare Modernization Act (MMA), which increased payments to managed care plans. Between 2001 and 2014, number of working poor covered by Medicaid numbered 42.2 million people (nearly $15 \%$ of the U.S. population)

2 An estimated 50 to 65 primary care givers per 100,000 in HMOs versus 70 to 80 primary care givers per 100,000 in fee-for-service sector (Cooper, 1994).

3 The future physician-to-population ratios suggested that the number of primary care physicians would be out-numbered 4 -to- 1 by 2012 , and current specialty selection of residents into specialties other than primary care (in 1994) inadequately distributed residents across the workforce spectrum. (McCutcheon, 2009) The fear among the AMA was an "enrollment explosion" (Cooper, 1994) in the number of physicians (as occurred in the 1970s), but any 'regulation and control thereof was antithetical to the concept of professionalism of physicians.' (Cooper, 1994; McCutcheon, 2009)

4 McCutcheon's research shows resident physicians choosing medical specialties based primarily on income level, but substantially supported by other life-style characteristics the specialty offers. (2009) 
and the number of elderly covered by Medicare was 15.5 million people (over $5 \%$ of the U.S. population). Nearly $20 \%$ of the country's population received health insurance by entitlement -products and services they perceived as "free." (Kongstvedt, 2016) Once again, the economic Law of Demand worked against the intention that single-payer medical insurance system is a "benefit" to the citizens of the country by negating the idea of "bending the cost curve down'. (Kongstvedt, 2016)

In March of 2010, the fifth step towards single-payer medical insurance system was taken when congress passed the Patient Protection and Affordable Care Act (ACA, but more commonly known as Obamacare). It is arguably the most sweeping alteration of the medical care industry since 1965. This law mandated that citizens purchase healthcare insurance, and in the absence of that purchase, citizens were fined. This was the first time in the history of the United States that citizens were forced to purchase a good or service. The 2009 ACA legislation violated the Interstate Commerce Clause of the US Constitution, and in 2017, the Individual Mandate was eliminated via Presidential Executive Order.

We assert that of the five steps to single-payer healthcare, Obamacare was the bridge too far for the majority of U.S. physicians. In 2012, Thousands of physicians, disillusioned with the lack of reimbursement for Medicare and Medicaid services rendered to the aged and poor, opted out from serving this cross-section of the insured. In the late 1960s the majority of physicians operated a solo-practice business and only a few physicians were part of a group practice, or were hospital employees. (McCutcheon, 2009) By 2012, the $75 \%$ of physicians were either in a group practice or employed directly by hospitals, and only a few physicians remained as solo-practitioners. (Jacob, 2014) Physicians were either closing their offices, or refusing to accept Medicare or Medicaid patients. One solo physician in Dallas, Texas, wrote to his patients that he would be discontinuing his practice due to the extreme reduction in Medicare and Medicaid reimbursements to his practice, which made it impossible for him to run his practice as a business. (Jacob, 2014) In 2014, a survey by Jackson Healthcare reported that one out of three physicians were planning to quit their practice by 2024 . (Jacob, 2014) Over 1,000 mergers and acquisitions occurred in the healthcare industry; mergers among physician practices were among the largest growth industries from 2011 to 2012. (Jacob, 2014) Scatigna's overview of the 1988 Resource-Based Relative Value Scale (RBRVS), which instituted price controls for the reimbursement of Medicare or Medicaid services, and the 1997 Sustainable Growth Rate price control scheme, which tied the growth in physician fees to GDP growth, revealed that price controls in any form failed to stabilize a market. (Scatigna, 2012) Clearly, physicians knew they could not run a business on the reduced reimbursement plans and price control schemes in the Medicare system and thus sought either relief or release from market failure imposed by congressional legislation. (Scatigna, 2012) Physicians can hardly be blamed for reacting in their own self-interest to poorly written legislative policy when even economists got it wrong: William Hsiao thought the RBRVS system would succeed in controlling Medicare spending. (Scatigna, 2012) This brings the reader's attention back to the main point of this discussion. In order for markets to function properly and be competitive they must remain decentralized and free from government meddling.

Physicians who wanted to stay in business and continue to practice medicine began to look at their options and found the answer in their own past history. Prior to all of the legislation passed by congress intended to "help" the majority of physicians were essentially country doctors. The hallmark of the country doctor was as a well-trained general practice physician, who made home visits, knew his patients very well, and offered a sliding scale of pricing for medical services. (McCutcheon, 2019 forthcoming) By the year 2010, the idea of a physician being a country doctor was thought to be quaint and obsolete.

\section{Direct Primary Care -the Alternative to Single-payer Healthcare}

In the late 1990s, Dr. Brian Forrest, a General Practice physician in Apex, NC, found himself frustrated with the mountains of insurance paperwork he was required to complete in order to serve his patients, and the constant demands by healthcare insurance companies to increase the number of patients he saw each day. Each day, he saw forty or more patients. Each patient had his undivided attention for about only eight minutes, six of which he spent filling out ICD-9 (or ICD-10) codes on the computer. ${ }^{5}$ If the patient had three complaints, two was the maximum the patient could get addressed in the eight-minute visit. Follow-up visits with patients were just as fast. Rarely did Forrest feel like he'd given the patient the amount of time necessary to listen to everything the patient had to say and respond to all their ailments. He loved the art of medicine, and the entire experience of being a physician, but with the associated paperwork and productivity demands by the insurance companies, this experience was spoiled. His desire, in studying medicine, was to help people be healthy; it was not to become a virtual employee of a healthcare insurance company.

Forrest's practice accepted a variety of healthcare insurance in payment for services rendered, but these companies put restrictions on his entire practice of

5 International Classification of Diseases, $9^{\text {th }}$ Revision. From the CDC The International Classification of Diseases (ICD) is designed to promote international comparability in the collection, processing, classification, and presentation of mortality statistics. https://www.cdc.gov/nchs/icd/icd 9.htm 
medicine. Physicians contracted with Health Maintenance Organizations were forbidden by the HMO from receiving a smaller payment for the office visit by patients without healthcare insurance. This meant that patients with healthcare insurance would pay a smaller fee for the office visit than the patient without healthcare insurance. It irritated Forrest that the patient without healthcare insurance would pay more than the patient with healthcare insurance. He was not allowed to let patients pay the amount of money they could afford to pay, and that irritated Forrest, because knew that people were foregoing visits because they couldn't afford to see a doctor.

Dr. Forrest realized that he was not happy with the entire situation. He was forced to see more patients than he would in a 'normal' medical practice. He was frustrated with the healthcare insurance laws he was forced to follow that did not allow him to charge a price the patient could afford to pay. While his medical practice was netting him approximately $\$ 90,000$ annually, it seemed to him that even though he was seeing about 200 patients a week, there must be some inefficiencies resulting in pecuniary leakage in the process, somewhere.

Dr. Forrest began an in-depth analysis of his medical practice and in an effort to build an overview of the medical practice market he surveyed 43 other providers in the Winston-Salem area. He found that in an average encounter with a patient with insurance, the medical practice billed the healthcare insurance company (on average) $\$ 94$. Forrest's billing secretary collected from the insurance company approximately $\$ 39$. But, Forrest knew he was seeing $40+$ patients a day, and with revenue of $\$ 39$ per patient, his practice should have been much more profitable. So, he asked the billing secretary to calculate how much money was spent to collect the $\$ 39$ from the insurance company. It turned out that Forrest's practice was spending $\$ 50$ per patient to collect the $\$ 39$ (collecting approximately 22-cents on the $\$ 1$ ). He was losing $\$ 11$ per patient; the more patients he saw, the more money he lost. He could not see enough patients to breakeven.

He decided that if he eliminated all of his contracts with the healthcare insurance companies, eliminated all of the extra employees in his practice, and did patient scheduling himself, he could see about ten patients a day and charge each patient about $\$ 40$ per visit. ${ }^{6}$ Forrest quickly took action to extract him from the healthcare insurance web, and transformed his medical practice into a for-profit business. He called his micro-practice Direct Primary Care.

6 As he tells the story, he realized that a gym membership was a good business model to follow. Gym members pay a monthly fee, and whether they go to the gym, or not, the membership fee is paid. He also realized that no gym employees followed each gym member around counting the number of times that person lifted a dumbbell to charge the member for each time he lifted the dumbbell at a $\$ 1$ per lift, or counted the number of times the gym member ran laps in the track to charge him a $\$ 1$ per lap. The ICD9 system, begun in 1900, and revised about every ten years, is exactly that process - following a patient's symptoms, and making a note for each symptom and charging the patient's healthcare insurance company for each ICD9 entry on the patient's chart.
In his micro-practice, he listed a menu of prices for office visits, prescriptions he would administer in the office visit, and other services. For chronically ill patients, he charged an extra $\$ 25$ per month, because the number of office visits by chronically ill people is greater than the number of office visits by the 'regular' patient (who may only be there for a wellness check or has a sore throat). He feared that his current load of patients would leave to find other physicians and he would lose a great number of his patients. Instead, he found that $95 \%$ of his patients stayed with him, because it was less expensive for them to pay him cash than for them to pay monthly premiums to the healthcare insurance company. He estimated that he could still earn approximately $\$ 90,000$ annually, and since that was the amount he had been earning in the previous (more frustrating and unhappy) practice, he would be satisfied.

About 18 months after he opened his micro-practice he did a follow-up analysis on his own business. He was collecting $99 \%$ of all his medical fees (collecting approximately 83 -cents on a $\$ 1$ ). He was seeing about 10 patients a day, for an average of 45 minutes to an hour (which made the patients really happy). His stress and frustration level was almost non-existent. He had more time to arrange his work-life balance to a happy equilibrium. $\mathrm{He}$ found he was extremely satisfied practicing medicine, and he was earning over $\$ 250,000$ annually. Astounded at his success of running a for-profit business, and because for-profit medical practices were still condemned by the AMA, he kept the secret to himself.

Validation that Forrest's micro-business model worked came one day when he walked into his waiting room and saw two men waiting. One man had driven two hours (one way) for his appointment. He was very wealthy and could afford to buy healthcare insurance, but the service he received from Forrest in his practice, for the $\$ 40$ office visit, was well worth the time in the car. Why should he spend thousands of dollars annually to see a physician in his own town for eight minutes? The second patient was a homeless man, who rode the bus thirty minutes to get to Forrest's office. He could not get Medicare or Medicaid because he was homeless, but if he could why should he? His $\$ 40$ office visit with Forrest was of higher quality and value than the eight minutes he would spend with any other insurance-accepting physician.

In 2005, at a convention, after addressing a group of physician colleagues, Forrest was encouraged to write an expose to let other physicians know that a better way had been found that actually worked. In 2007, Dr. Forrest wrote an article in a medical journal titled, "Breaking even on four patients a day." ${ }^{7}$ At this time there were only five or six Direct Primary Care practices in the nation. But, the secret was out. At first, on occasion (perhaps once a month), a physician would call Forrest and ask what they could do

7 Forrest BR. "Breaking even on four patients a day," Family Practice Management. 2007; 14(6): pp.19-24. 
to escape the failing medical insurance system. Forrest would take a few hours on Saturday to hold a one-on-one session for the physician. Over the next five years, the trickle of family practice physicians seeking a return their practices to real medicine, increased to the point where Forrest would see patients Monday through Thursday, and spend Friday holding all-day seminars to teach other physicians how to start their own micro-practice.

To combat the anti-competitive nature of Obamacare, Dr. Forrest and his consortium of family physicians formed a network in 2010 founded upon the belief that family and general practice medical care could be provided at very inexpensive monthly subscriptions. This network of family practice physicians was made up of the thousands of physicians fleeing from administrative paperwork, long practice hours with limited time for patients, and very low payments forced on them by Medicare and Medicaid laws and healthcare insurance companies. They fled from membership in the AMA, whose edicts were forcing physicians to ignore the laws of supply and demand and the price mechanism. This group of family and general practice physicians gathered together and developed their own medical businesses in family medicine, and called their coalition Direct Primary Care (DPC).

The hallmark of DPC is transparent pricing and inexpensive monthly membership fees on a sliding scale based on primarily patient age, and secondarily on ability to pay. This rebirth of the sliding scale, monthly subscription form of medical practice has the effect of reducing the price consumer-patients pay for family practice medical care by 75 -to- 80 percent. 8 As one family physician recently told a class of practicing Nurse Anesthetists in a Doctoral Business Administration course, stating "I'm just a country doctor. I am free to work with my patients at competitive market prices so they can afford the medical care they need. It's twenty-first century medicine the old fashioned way." In rural communities, the return and restoration of the concierge country doctor, who responds to market conditions of supply, demand, and market prices, means that affordable healthcare is within reach. (McCoy, 2019)

\section{How DPC Works - Two Sample Patients in Direct Primary Care Models}

Two sample patients may suffice as examples of the services offered in DPC. (McCoy, 2019) ${ }^{9}$

First example: Patient Janet. Janet is a 58 year-old diabetic (see Table 1). Under the DPC plan, over the course of one year, for regular medical care, she pays to the physician approximately $\$ 843$. If she was a patient of a non-DPC physician she could expect to pay, out of her own pocket, nearly $\$ 2678$ for the same services. Under the DPC plan, for basic health care, Janet avoided paying \$1835, which she could spend elsewhere, or save.

If Janet contracts pneumonia during the year, under the care of a DPC physician, her additional cost is $\$ 90$. Under the care of a non-DPC physician, she could expect to pay an additional $\$ 745$, bringing her annual total out-of-pocket expenses to $\$ 3423$.

Why are the prices so high for medical care under the non-DPC physician, when Janet is supposed to also have health care insurance? Because, in the non-DPC model -the regular health insurance model our country's insurance companies have been using for the last $50+$ years, Janet must reach the limit of her insurance plan's deductible before the insurance company will pay for any of her medical care. In other words, if Janet's deductible were $\$ 6000$ (which is the national average for individuals with health care insurance), Janet would still have to spend an additional $\$ 2577$ before her health care insurance company would pay for any additional health care.

Under the care of a Direct Primary care physician, Janet's total amount of money out of her pocket for an average year, with one bout of pneumonia, is approximately $\$ 933$. Under the care of a DPC physician, Janet did not spend an additional \$5067. She did not spend an amount of money approximately equal to $\$ 422$ per month! 
Table 1. Patient Janet

\begin{tabular}{|c|c|c|}
\hline Description of visit & Insurance & Direct Primary Care \\
\hline $\begin{array}{l}\text { Wellness exam-since Janet } \\
\text { has diabetes, she visits } 2-4 x\end{array}$ & $\begin{array}{c}\$ 185 / \text { visit } \\
4 \text { visits/year }=\$ 740\end{array}$ & $\$ 65 / \mathrm{mo}=\$ 780$ \\
\hline Annual Labs & $\$ 825$ and up & No charge \\
\hline Quarterly DM visit & $\$ 740 /$ year & No Charge \\
\hline Venipuncture & $\$ 23 \times 4=\$ 92$ & No charge \\
\hline Lisinopril & $\$ 115.80 /$ year & $\$ 4.69 /$ year \\
\hline Metformin & $\$ 48 /$ year & $\$ 12.32 /$ year \\
\hline Atorvastatin & $\$ 62 /$ year & $\$ 36 /$ year \\
\hline Flu shot & $\$ 55$ & $\$ 10$ \\
\hline Total cost to patient & $\begin{array}{l}\text { \$2677.80 (and up) out-of-pocket if patient has } \\
\text { not reached her deductible }\end{array}$ & $\begin{array}{c}\quad \$ 843.01 \text { out-of-pocket } \\
\text { (a savings of } 68.5 \% \text { over the health insurance model) }\end{array}$ \\
\hline \multicolumn{3}{|l|}{ Janet has Pneumonia } \\
\hline Description of visit & Insurance & Direct Primary Care \\
\hline Pneumonia visit & $\$ 185$ and up & Free -no charge for visit \\
\hline Chest X-ray & $\$ 210$ & $\$ 85$ \\
\hline Antibiotic & $\$ 230$ & $\$ 5$ \\
\hline Follow-up visit & $\$ 120$ & Free -no charge for visit \\
\hline Total cost to patient & $\$ 745$ & $\$ 90$ \\
\hline Total cost to patient & $\begin{array}{l}\$ 3422.80 \text { : is out-of-pocket; } \\
\text { avg deductible for individual } \approx \$ 6,000 \text {, so } \\
\text { Janet must pay out-of-pocket an additional } \\
\$ 2577.20 \text { before her insurance will pay for any } \\
\text { medical care. }\end{array}$ & $\begin{array}{l}\$ 933.01 \text { out-of-pocket } \\
\text { Janet saved } \$ 2489.79 \text {, a savings of } 72.74 \% \text {; } \\
\text { Janet has no deductible, so compared with the costs she } \\
\text { would pay out-of-pocket under a health insurance plan, } \\
\text { she's saved } 84.5 \% \text { of her money, a total of } \$ 5066.99\end{array}$ \\
\hline
\end{tabular}

Table 2. Patient Sherry

\begin{tabular}{|c|c|c|}
\hline Description of visit & No Health Insurance & Direct Primary Care \\
\hline $\begin{array}{c}\text { Wellness exam-since Sherry has high blood } \\
\text { pressure, she visits } 2-4 x\end{array}$ & $\$ 185 /$ visit 4 visit $/$ year $=\$ 740$ & $\$ 65 / \mathrm{mo}=\$ 780$ \\
\hline Annual Labs & $\$ 825$ and up & No charge \\
\hline Quarterly DM visit & $\$ 740 /$ year & No Charge \\
\hline Blood pressure meds & $\$ 58 / \mathrm{mo}=696$ & $\begin{array}{c}\$ 5.43 / \mathrm{mo}=\$ 65.16 \\
\text { Saving her } \$ 52.57 / \mathrm{mo}\end{array}$ \\
\hline Flu shot & $\$ 55$ & $\$ 10$ \\
\hline Total cost to patient & $\begin{array}{c}\$ 3056 \text { out-of-pocket patient has no health } \\
\text { insurance }\end{array}$ & $\$ 855.16$ out-of-pocket \\
\hline \multicolumn{3}{|l|}{ Sherry has Pneumonia } \\
\hline Description of visit & No Health Insurance & Direct Primary Care \\
\hline Pneumonia visit & $\$ 185$ (est. cost of ER visit) & Free -no charge for visit \\
\hline Chest X-ray & $\$ 210$ & $\$ 85$ \\
\hline Antibiotic & $\$ 230$ & $\$ 5$ \\
\hline Follow-up visit & $\$ 120$ & Free -no charge for visit \\
\hline Total cost to patient & $\$ 745$ & $\$ 90$ \\
\hline Total cost to patient & $\begin{array}{l}\$ 3801 \text { (at the very least) is out-of-pocket; no } \\
\text { peace of mind because she has no health } \\
\text { insurance and no way to afford healthcare } \\
\text { through her employer or Obamacare. }\end{array}$ & $\begin{array}{l}\text { \$945.16 paid out-of-pocket; } \\
\text { saved } \$ 2855.84 \text {-a } 75.13 \% \text { savings } \\
\text { over having no health insurance }= \\
\text { Peace of mind because she has basic } \\
\text { medical care coverage }\end{array}$ \\
\hline
\end{tabular}


Second example: Patient Sherry. Sherry is a female between the ages of 41 and 64, with high blood pressure. (Table 2) Sherry's income is too high to be on Medicaid, but too low afford the health care insurance offered by her employer. She has no insurance, but she does have a DPC physician. Sherry's total health care for an average year under the care of a DPC physician is approximately $\$ 855$. But, if she had no DPC physician, her blood pressure medicine alone would cost her $\$ 58$ a month, which is $\$ 696$ a year. Sherry's DPC physician is only costing her an additional \$13.25 per month. Under the care of Sherry's non-DPC physician, her annual cost out of her own pocket for regular health care, would be in excess of $\$ 3050$, which is $\$ 255$ each month.

Sherry could ill afford to have the same bout of pneumonia that Janet had were she still under the care of a non-DPC physician. The additional $\$ 745$ out of her pocket for the non-DPC physician services would increase her financial burden. When Sherry found the local DPC physician in her area, she immediately recognized the value added to her life from the DPC model.

\section{Is the Direct Primary Care Business Model Successful?}

According to Medscape's Physician Compensation Report for 2016, cash-only practices were operated by 6-percent of physicians in their survey. That is a 100-percent increase over the number of physicians operating cash-only practices in 2012. (Peckham, 2016) The number of physicians operating cash-only and Direct Primary Care practices were 18-percent of all physicians in the Medscape Physician Compensation Report for 2018, a 300-percent increase in two years. (Kane, 2018)

Cash-only and Direct Primary Care physicians can expect to earn approximately 50-percent higher income than physicians working in group practice that do business with health care insurance companies. In 2018, Medscape 2018 Physician Compensation reported that a non-Direct Primary Care physician could expect to earn approximately $\$ 223,000$, while a DPC physician could expect to earn $\$ 330,000$. (Kane, 2018) With a patient load of 500-600 patients, even DPC physicians in rural areas earn more than the non-DPC physician. Physicians are flooding into this new area of medicine.

Additionally, Direct Primary Care physicians have more control over their work life, choosing to spend approximately 20-to-30 hours per week in direct patient care, rarely working more than 40-hours per week in toto. (Lamberts, 2015; Radcliffe, 2017, McCoy, 2019) Non-DPC physicians, both in group practice and as hospital employees, work on average in excess of 45-50 hours each week. (McCutcheon, 2009) According to DPC physicians, the majority of their time is spent seeing patients, with very little time spent filling out paperwork for insurance companies. Non-DPC physicians experience the exact opposite as the majority of their time is spent filling out required paperwork for insurance companies, after the two or three minutes is spent with the patient. (Lambert, 2015; Radcliffe, 2017; McCoy, 2019)

The state and federal governments are moving to pass legislation to expand access to high functioning primary care services for Americans of all income and age levels. The Primary Care Act (H.R. 365 and S. 1358) clarifies the tax code to remove major federal regulatory barriers that keep patients, providers and employers who use Health Savings Accounts (HSAs) from using innovative Direct Primary Care medical homes to reduce costs and improve health outcomes. (DP Care Coalition, 2019) As of this writing, 23 states have designed and implemented laws that generally define DPC as a medical service outside of state insurance regulation, offering varying levels of consumer protection. (DP Care Coalition, 2019)

At the time of this writing, the Internal Revenue Service (IRS) only recognizes DPC as a form of health plan, where an individual with an agreement with a DPC physician is barred from using HAS funds to pay the monthly subscription. We expect that as more people join these types of physician business model, this aspect of Direct Primary Care will change.

\section{Conclusions}

The brief history of the five major government medical insurance policies enacted since 1942 reveals that the intention behind the acts was to lead the United States gradually in the direction of a single-payer medical system. A single-payer system is by definition a medical monopoly, promoted, supported, and enforced by the government. Physicians are not benefited by this system as production quotas by healthcare insurance companies force them to increase the number of patient appointments to the point where very little quality time is spent with the patient addressing their medical condition. The patient is not benefited by this system as their physicians have very little time to address their medical concerns. The physician's practice does not benefit because it costs more money to chase down the insurance reimbursement than the reimbursement itself. Patients do not benefit because they pay a very high monthly premium with little value to show for it. The only institutions that benefit by these five major government medical insurance policies are the healthcare insurance companies. With extraordinarily little effort they receive monthly premiums from patients, reimburse physicians for only a small portion of the cost of the patients' office visit, while keeping in their own coffers the majority of the money.

This research reveals the brief history of the events that inspired Dr. Brian Forrest to conceive and implement an entrepreneurial micro-business benefiting himself and his 
patients. The Direct Primary Care business model offers physicians the opportunity to practice medicine in the way that is best for the patient, while running a profitable business. Patients benefit because they receive high quality healthcare while paying a very low price for it. Physicians benefit because they have the opportunity to practice high quality medicine, while at the same time lower their stress and frustration levels by balancing their work and life situations. Two sample patients, with their associated costs for medical care are offered for the reader's consideration of the simplicity of the DPC model. Since case studies of this business model and distribution of healthcare model are unavailable, we will continue our research in the form of case studies at the local, state, and national levels to evaluate the efficacy and efficiency of both the business and healthcare distribution models.

Economists know that the hallmark of a decentralized competitive market is a plethora of substitute goods and services offered by many small business enterprises resulting in low market prices. Consumer demand drives competition among businesses to create and offer to consumers the very best of products or services at competitively low prices. These same characteristics will work in a competitive medical market, too.

The only way to have true, affordable, healthcare is to increase the number of small business entrepreneurial family physicians in the medical market where the forces of consumer-patient demand, physician labor supply, transparent pricing and menu lists determine the true market price of medicine.

\section{REFERENCES}

[1] Baker PhD, Robert B., Harriet A. Washington BA, Ololade Olakanmi BA, Todd L. Savitt PhD, Elizabeth A. Jacobs MD MPP, Eddie Hoover MD, Matthew K. Wynis MD MPH, "African American Physicians and Organized Medicine, 1846-1968 - Origins of a Racial Divide," Journal of American Medical Association, Vol. 300, NO. 3, July 16, 2008, pp. 306-313.

[2] Bergen, Jr. MD, Stanley S., "Underrepresented Minorities in Medicine," JAMA, Vol. 284, No.9, September 2000, pp. $1138-1139$.

[3] Brotherton, Sarah E.; Frank A. Simon MD; Syliva I. Etzel; "US Graduate Medical Education, 2001-2002 - Changing Dynamics," JAMA, Vol. 288, No. 9. September 2002, pp. 1073-1078.

[4] Brotherton, Sarah E.; Paul H. Rockey MD; Syliva I. Etzel; "US Gradaute Medical Education, 2003-2004," JAMA, Vol. 292, No. 9, September 2004, pp. 1032-1037.

[5] Brotherton, Sarah E.; Paul H. Rockey MD; Syliva I. Etzel; "US Graduate Medical Education, 2005-2005 - Trends in Primary Care Specialties," JAMA, Vol. 294, No. 9, September 2005, pp. 1075-1082.
[6] Cohen MD, Jordan J., "Finishing the Bridge to Diversity," Academic Medicine, Vol. 72, No. 2, February 1997, pp. 103-109.

[7] Cooper MD, Richard A., "Seeking a Balanced Physician Workforce for the $21^{\text {st }}$ Century," JAMA, Vol. 272, No. 9, September 1994, pp. 680-687.

[8] Davis MD, Ronald M., "Achieving Racial Harmony for the Benefit of Patients and Communities," Journal of American Medical Association (JAMA), Vol. 300, No. 3, July 16, 2008, pp. 323-325

[9] Direct Primary Care Coalition, "H.R.365 and S.1358, The Primary Care Enhancement Act," Federal Policy Issues, https://www.dpcare.org/specialties (downloaded 1/3/2019)

[10] Dunn MD, Marvin R.; Rebecca S. Miller, Thomas H. Richter; "Graduate Medical Education, 1997-1998," JAMA, Vol. 280, No. 9, September 1998, pp. 809-812

[11] Forrest, Brian, MD., (2019) Interview on January 14, 2019.

[12] Goldin, Claudia, and Lawrence F. Katz., "The Power of the Pill: Oral Contraceptives and Women's Career and Marriage Decisions," The Journal of Political Economy, Vol. 110, No. 4, August 2002, pp. 730-770.

[13] Hall, M. A., \& Schneider, C. E. "Learning from the legal history of billing for medical fees," Journal of General Internal Medicine, Vol. 23, No. 8, April 2008, pp. 1257-60.

[14] Jacob, Steve, "Facing an Uncertain Future, Physicians Increasingly Throw in the Towel," Healthcare Magazine, August 27, 2014.

[15] Jonas MD, Harry S.; Sylvia I. Etzel; Barbara Barzansky; "Educational Programs in US Medical Schools," JAMA, Vol. 270, No. 9, September 1993, pp. 1061-1068.

[16] Kane, Leslie, "Medscape Physician Compensation Report 2018," Medscape, April 11, 2018, https://www.medscape.c om/slideshow/2018-compensation-overview-6009667 (downloaded 1/8/2019)

[17] Kongstvedt, Peter R., Health Insurance and Managed Care, $4^{\text {th }}$ Edition, Jones \& Bartlett Learning, Burlington, Massachusetts, 2016.

[18] Lamberts, M.D., Robert, "My Direct-Pay Primary-Care Practice: 2 Years Out," Physicians Practice, February 12, 2015, http:/www.physicianspractice.com/practice-models/ my-direct-pay-primary-care-practice-2-years-out (downloa ded $1 / 3 / 2019$ )

[19] Ludmerer MD, Kenneth M.; Michael M.E. Johns MD; "Reforming Graduate Medical Education," JAMA, Vol. 294, No. 9, September 2005, pp. 1083-1087.

[20] McCoy, D.O., Lori. Solo Practice owner of Advanced Primary Care, Flatwoods, Kentucky, Interviewed: January 8,2019 .

[21] McCutcheon, Robin S., "Specialty Choice of Black and non-Black resident Physicians: An Occupational Choice Model," PhD Dissertation. Wayne State University, Detroit, Michigan. Copyright 2009.

[22] McCutcheon, Robin., "The issue of Monopolization of physician labor supply in the United States," working paper. 
[23] Miller MS, Rebecca S.; Marvin R. Dunn MD; Thomas Richter MS; "Graduate Medical Education, 1998-1999 - A Closer Look," JAMA, Vol. 282, No. 9, September 1999, pp. 855-860.

[24] Newton MD, Dale A.; Martha S. Grayson MD; "Trends in Career Choice by US Medical School Graduates," JAMA, Vol. 290, No. 9, September 2003, pp. 1179-1182.

[25] Nickens, H W., T. Ready, and R. Petersdorf., "Project 3000 by 2000 - Racial and Ethnic Diversity in U.S. Medical Schools," New England Journal of Medicine, Vol. 331, August 18, 1994, pp. 472-476.

[26] Peckham, Carol, "Medscape Physician Compensation Report 2016," Medscape, April 1, 2016 , https://www.medscape.com/features/slideshow/compensati on/2016/public/overview\#page=19 (downloaded 1/7/2019)

[27] Petersdorf MD, Robert G., "Not a Choice, an Obligation," Academic Medicine, Vol. 67, No. 2, February 1992, pp. 73-79.

[28] Radcliffe, Shawn, "These Doctors Accept Only Cash," Healthline, March 1, 2017, https://www.healthline.com/he alth-news/these-doctors-accept-only-cash\#1 (downloaded $1 / 3 / 2019)$

[29] Rivo MD, Marc L.; Huey L. Mays MD; Jerald Katzoff; David Kindig MD; for the Council on Graduate Medical Education; "Managed Health Care-Implications for the Physician Workforce and Medical Education," JAMA, Vol. 274, No. 9, September 1995, pp. 712-715.

[30] Scatigna, Lou., "How Obamacare's \$716 Billion in Cuts Will Drive Doctors Out of Medicare," Forbes, August 20, 2012.

[31] Scofea, Laura A., "The development and growth of employer-provided health insurance," Monthly Labor Review, March 1994, pp. 3-10.

i This research did not receive any specific grant from funding agencies in the public, commercial, or not-for-profit sectors. 